\title{
A two-step mode of stripe formation in the Drosophila blastoderm requires interactions among primary pair rule genes
}

\author{
Christine Hartmann, Heike Taubert, Herbert Jäckle ${ }^{*}$ and Michael J. Pankratz \\ Abteilung Molekulare Entwicklungsbiologie, Max-Planck-Institut für Biophysikalische Chemie, Postfach 2841, D-37018 Göttingen, Germany
}

(Received 16 August 1993; revision received and accepted 26 August 1993)

\begin{abstract}
The stripe pattern of pair rule gene expression along the anterior-posterior axis of the Drosophila blastoderm embryo represents the first sign of periodicity during the process of segmentation. Striped gene expression can be mediated by distinct cis-acting elements that give rise to individual stripe expression domains in direct response to maternal and first zygotic factors. Here we show that the expression of stripes can also be generated by a different, two-step mode which involves regulatory interactions among the primary pair rule genes hairy $(h)$ and runt (run). Expression of $h$ stripes 3 and 4 is directed by a common cis-acting element that results in an initial broad band of gene expression covering three stripe equivalents. Subsequently, this expression domain is split by repression in the forthcoming interstripe region, a process mediated by a separate cis-acting element that responds to run activity. This second mode of pair rule stripe formation may have evolutionary implications.
\end{abstract}

Key words: Interstripe repressor element; Stripe formation; Pair rule gene

\section{Introduction}

The segmented body pattern of Drosophila is laid down early in embryogenesis through the action of different classes of genes (Nüsslein-Volhard and Wieschaus, 1980; Nüsslein-Volhard et al., 1982). The maternal coordinate genes establish global embryonic polarity, the gap genes subdivide the embryo into a series of broad regions, the pair rule genes generate double segment periodicity, and the segment polarity genes generate patterns in each segment. Within this cascade, the appearance of the striped expression of the pair rule genes marks the first sign of a periodic pre-pattern that underlies the segmental organization of the embryo (Akam, 1987; Ingham, 1988; Carroll, 1990; Howard, 1990; Pankratz and Jäckle, 1990).

Based on regulatory interactions among each other, the pair rule genes have been subdivided into two classes (Howard and Ingham, 1986; Carroll and Scott, 1986). The primary pair rule genes, such as hairy $(h)$, runt (run), and even-skipped (eve), are expressed in

* Corresponding author. repetitive patterns of seven individual stripes, and their activities then provide the periodic spatial cues for generating the striped expression pattern of the secondary pair rule genes, such as fushi tarazu ( $f t z)$ (Howard and Ingham, 1986; Carroll and Scott, 1986; Harding et al., 1986; Frasch and Levine, 1987; Ingham and Gergen, 1988; Carroll and Vavra, 1989). Genetics combined with molecular analysis of the $h$ and eve control regions showed that the majority of the stripe expression domains of the two genes are independently regulated by separate cis-acting elements responding to maternal and gap gene activities (Howard et al., 1988; Goto et al., 1989; Harding et al., 1989; Hooper et al., 1989; Pankratz et al., 1990; Howard and Struhl, 1990; Riddihough and Ish-Horowicz, 1991; Small et al., 1991; Lardelli and Ish-Horowicz, 1993). A detailed molecular analysis of the second stripe of eve indicated that this stripe element is activated by the anterior morphogens bicoid (bcd) and hunchback ( $h b)$; the initially broad stripe of expression is then repressed from the anterior and posterior by the combined action of the gap gene giant $(\mathrm{gt})$ and Krüppel $(\mathrm{Kr})$, respectively (Goto et al., 1989; Stanojevic et al., 1989; 1991; Small et al., 1990, 1992). Similarly, the sixth stripe of $h$ 
also appears to be formed by the combined activating and repressing activities of gap genes products (Pankratz et al., 1990; Riddihough and Ish-Horowicz, 1991). These studies gave rise to the current paradigm that the stripe expression pattern of primary pair rule genes is mediated by a series of modular stripe elements which respond individually to the overlapping maternal and gap gene activities (for review see Pankratz and Jäckle, 1993).

In this paper we show that the expression of $h$ stripes 3 and 4 is controlled by a common cis-acting element leading to a broad gap gene-like expression domain. This initial expression domain is then split by repression through the activity of another primary pair rule gene, run, that acts through a separate cis-acting interstripe repressor element. This 'two step mode' differs from the currently favoured mechanism of stripe formation, and it provides evidence for mutual interactions among the primary pair rule genes with implications on the segmentation process during insect evolution.

\section{Results}

The gene $h$ is expressed in a series of seven stripes spanning the region of the trunk primordia in the blastoderm embryo. $h$ stripes 3 and 4 , in contrast to the others that arise singly, derive from an initially broad expression domain which resolves into two separate and evenly spaced stripes at late blastoderm (Howard, 1988; Hooper et al., 1989; Pankratz et al., 1990).

\subsection{Cis-regulatory sequences controlling $h$ stripe 3 and 4 expression}

The regulatory region responsible for $h$ stripe 3 and 4 expression has been previously mapped to a $1.7 \mathrm{~kb}$ DNA fragment which is located approximately $12 \mathrm{~kb}$ upstream of the $h$ coding sequence (Pankratz et al., 1990; Howard and Struhl, 1990; Riddihough and IshHorowicz, 1991). When this $1.7 \mathrm{~kb}$ DNA fragment is fused to the bacterial lac Z gene (h-C/C lac Z, Fig. 1),

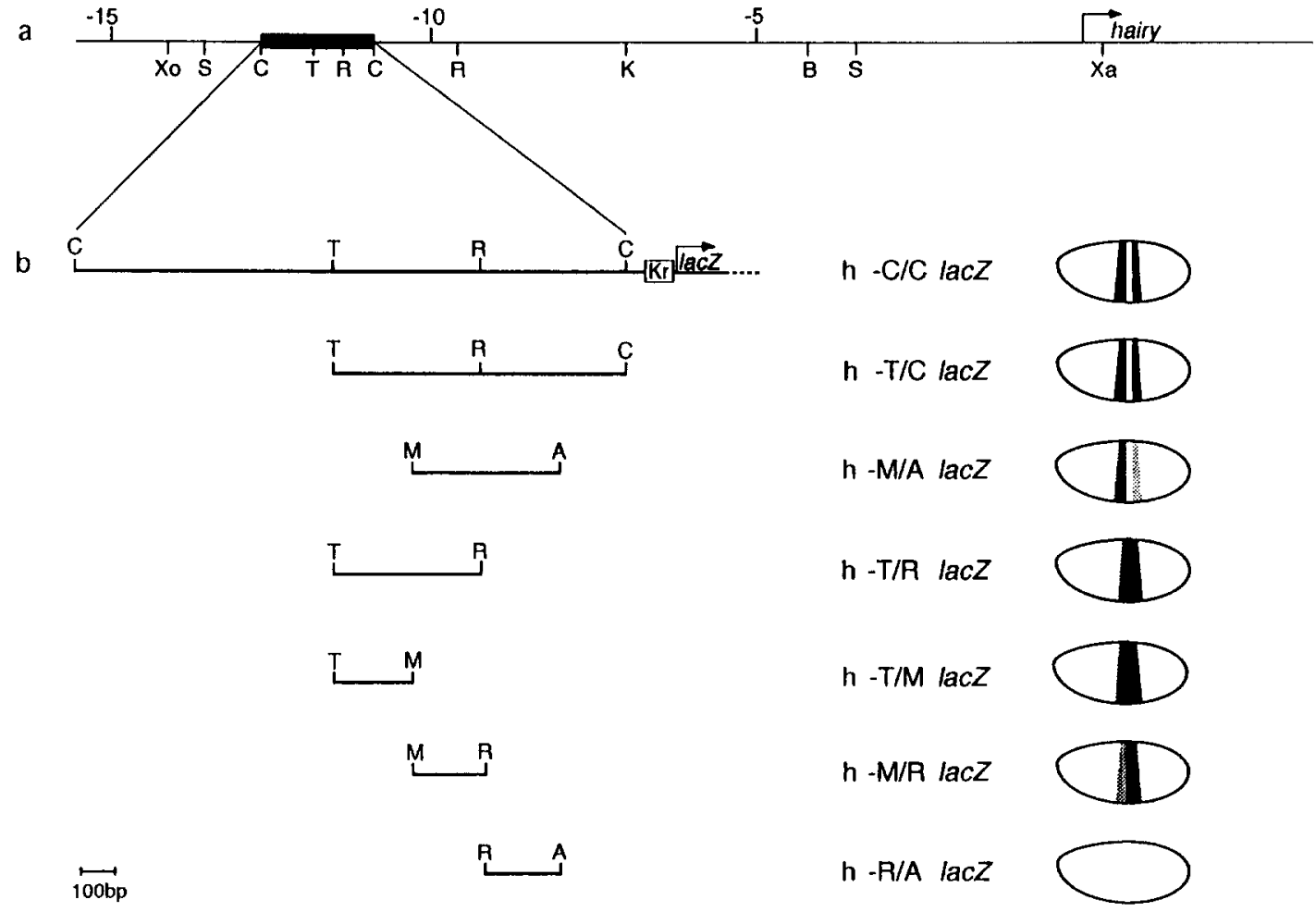

Fig. 1. Summary of $\mathrm{h}$-lac $Z$ fusion gene constructs and their corresponding blastoderm expression patterns. (a) Partial restriction map of the $15 \mathrm{~kb}$ $h$ upstream region (Rushlow et al., 1989). The arrow marks the transcription start of $h$. The black bar indicates the ClaI DNA fragment which drives reporter gene expression in position of $h$ stripes 3 and 4. (b) Different DNA fragments derived from the genomic ClaI fragment (see a) used for the construction of the various h-lac $Z$ fusion genes. $\beta$-galactosidase expression patterns conducted by the different DNA fragments are shown schematically on the right. The relative strength of the $\beta$-galactosidase expression is indicated by the degree of shading. All fragments have been linked to the basal $K r$ promotor fused to the lac $Z$ gene (see Materials and Methods). For details on the $\beta$-galactosidase expression patterns directed by the different DNA fragments see text and Fig. 2. Restriction enzyme sites are A, AvaI; B, Bam HI; C, ClaI, K, KpnI; M, $M l u$ I; R, EcoRI; S, Sal I; T, StuI; Xa, XbaI; Xo, XhoI. 
it mediates expression of the reporter gene in the area of endogenous $h$ stripe 3 and 4 expression domains in transgenic embryos (Fig. 2a). In order to separate the regulatory elements for the stripe 3 and 4 expression as accomplished previously for other primary pair rule stripe elements (Goto et al., 1989; Harding et al., 1989; Pankratz et al., 1990; Howard and Struhl, 1990; Riddihough and Ish-Horowicz, 1991), and to identify the sequence requirement for each of the two stripe expression domains, we took smaller portions from the $1.7 \mathrm{~kb}$ DNA fragment and assayed for their ability to direct reporter gene expression in transgenic embryos.

In wildtype embryos, the construct $\mathrm{h}-\mathrm{T} / \mathrm{C}$ lac $\mathrm{Z}$ (Fig. 1b) was expressed in a striped expression pattern indistinguishable from the one directed by the $1.7 \mathrm{~kb}$ element (Fig. 2b). This indicates that sequences contained within the $900 \mathrm{bp} h$ upstream fragment are sufficient to provide the normal spatial limit of the $h$ stripe 3 and 4 expression domains. The $\mathrm{h}-\mathrm{T} / \mathrm{R}$ lac $\mathrm{Z}$ transgene (Fig. 1b) expression domain covers an area which is slightly smaller than the area covered by $h$ stripe 3 and 4 expression, but it did not resolve into separate stripes (Fig. 2c; see also (Howard and Struhl, 1990)). Similar patterns of expression were also observed with the $\mathrm{h}-\mathrm{T} / \mathrm{M}$ lac Z and $\mathrm{h}-\mathrm{M} / \mathrm{R}$ lac Z transgenes (Fig. 2e,f), while the construct h-M/A lac Z directed a two striped expression pattern, although with low intensity (Fig. 2d). No signs of lac Z expression could be observed with construct h-R/A lacZ (data not shown). Thus, sequences within the $240 \mathrm{bp} \mathrm{T/M}$ fragment and the $220 \mathrm{bp} \mathrm{M} / \mathrm{R}$ fragment are each sufficient to mediate gene expression in a single broad band, whereas se-
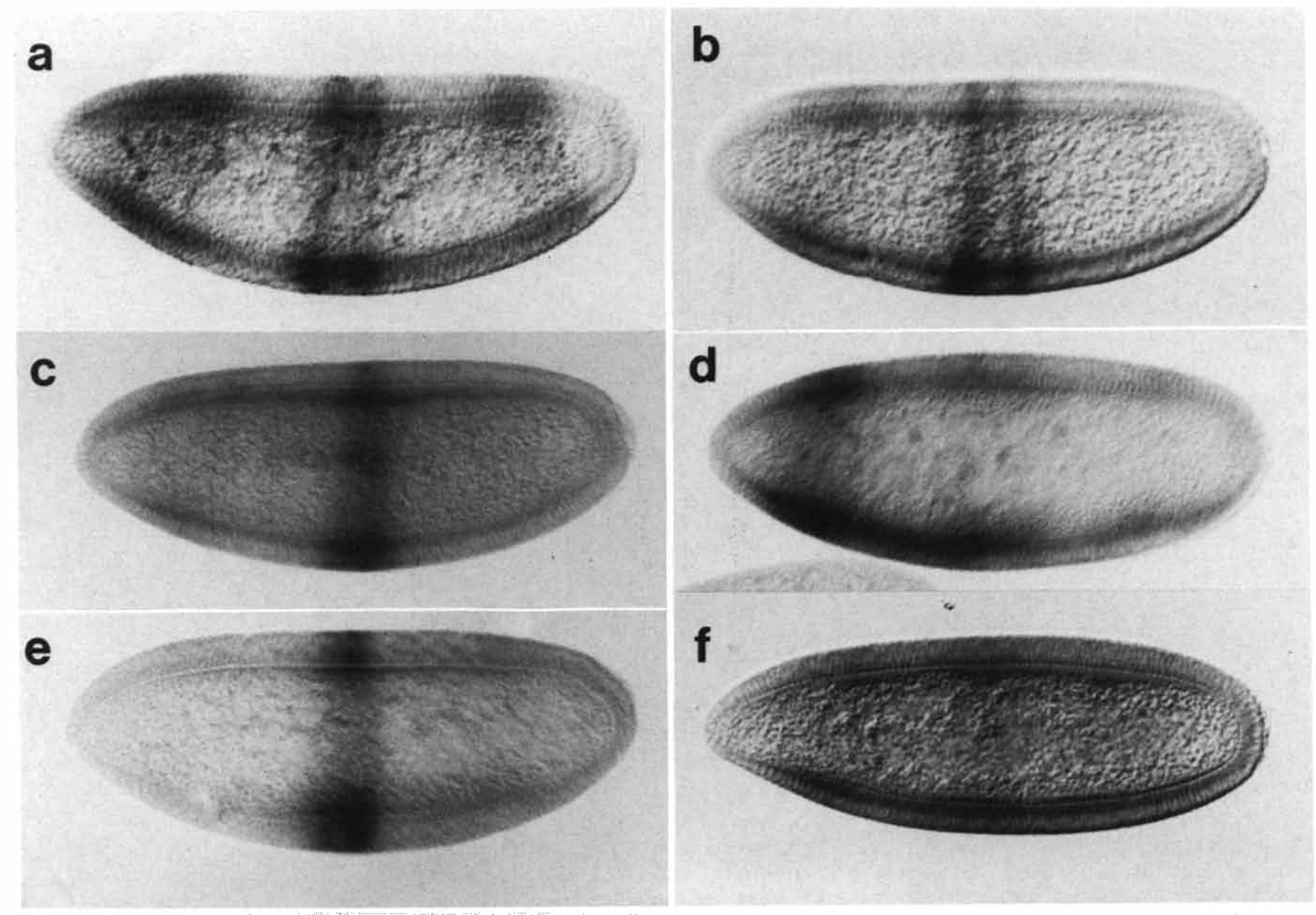

Fig. 2. $\beta$-galactosidase expression patterns driven by $c i s$-acting elements derived from the $h$ upstream region. (a) The h-C/C lac $Z$ fusion gene construct directs two stripes of $\beta$-galactosidase expression in the area of the endogenous $h$ stripes 3 and 4 . (b) The h-T/C lac $Z$ fusion gene construct directs $\beta$-galactosidase expression in two stripes indistinguishable from the pattern observed in (a). Doublestaining with anti- $\beta$-galactosidase- and anti- $h$-antibodies indicates that the two stripes are located in the area of endogenous $h$ stripes 3 and 4 (data not shown). (c) The $\mathrm{h}$-T/RI lac $Z$ drives $\beta$-galactosidase expression in a broad, central band. Based on doublestaining, this band of expression is located approximately from $h$ stripe 3 to the posterior border of $h$ stripe 4 (data not shown). (d) The h-M/AI lac $Z$ construct directs a weak, striped $\beta$-galactosidase expression pattern in the middle of the embryo. (e) The construct $\mathrm{h}-\mathrm{T} / \mathrm{M}$ lac $Z$ drives $\beta$-galactosidase expression in a broad band, similar to the expression pattern of h-T/RI lac $Z$ seen in (c). (f) h-M/RI lac $Z$ directs a weak, broad band of $\beta$-galactosidase expression in the middle of the embryo. The anterior domain of $\beta$-galactosidase expression at approximately $75 \%$ egg length that can be observed in some of the constructs is due to sequences of the $\mathrm{pCaSpeR}$ vector (Weigel et al., 1990). Some constructs also show a weak staining in the posterior region. 
quences within the downstream adjacent $235 \mathrm{bp} R / \mathrm{A}$ fragment are essential for the separation of a broad band into two stripes. These results suggest that $h$ stripe 3 and 4 expression is activated in a broad domain (the ' $h$ stripe $3 / 4$ ' expression domain) under the control of a single $h$ cis-acting element, and that the generation of two stripes depends on a different and separable element which mediates local repression in the interstripe region. We refer to this element as the interstripe repression element ('ISR-element').
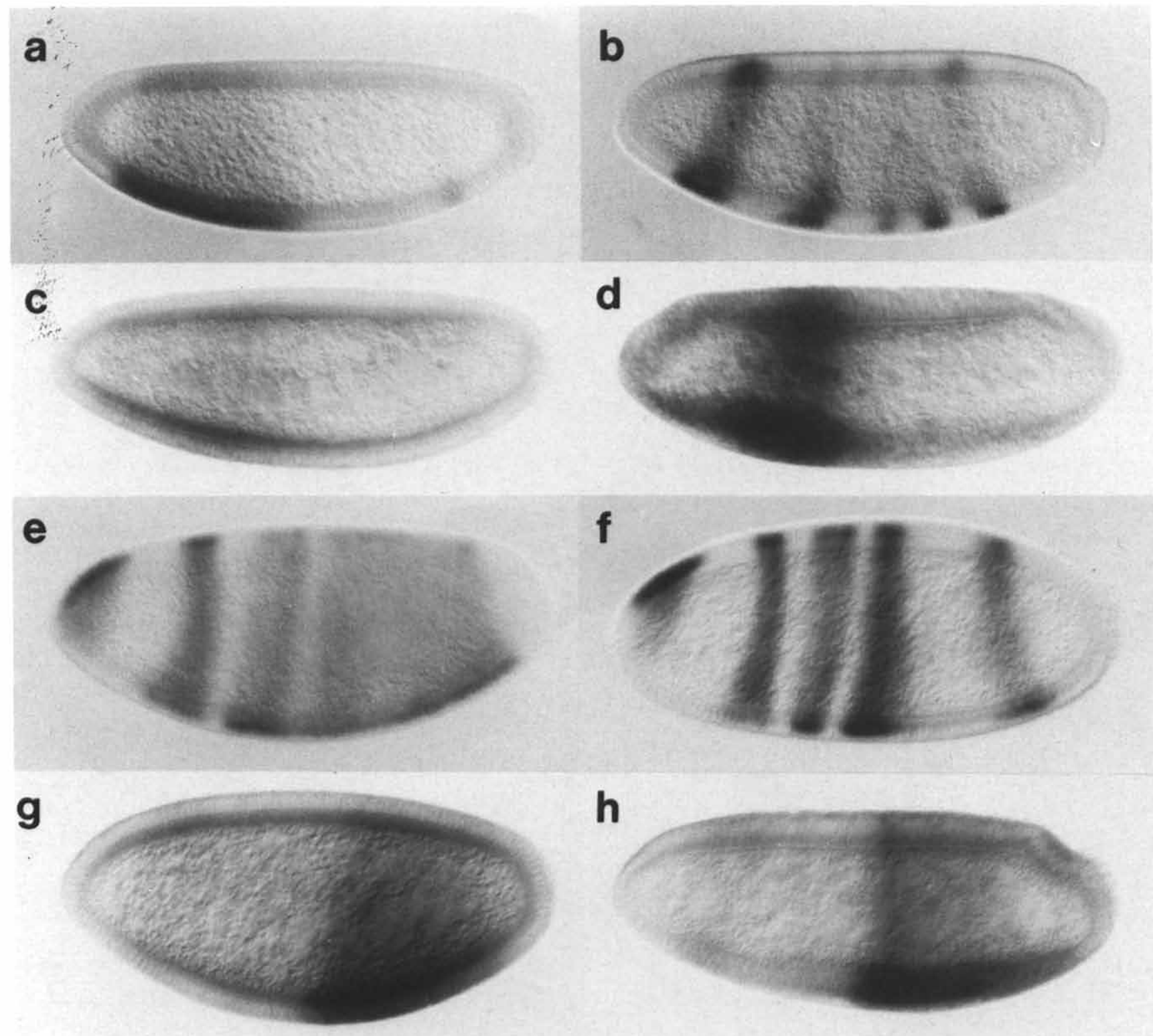

Fig. 3. Expression patterns of endogenous $h$ and the fusion gene construct h-T/C lac $Z$ in embryos lacking bcd or nos activity. During blastoderm stage dynamic changes in the expression pattern of endogenous $h$ in embryos from mothers homozygous for $b c d$ (a,b) or nos (e,f) can be observed. At early blastoderm stage, the embryos lacking $b c d$ activity show a broad domain of $h$ expression first seen in the anterior part of the embryo (not shown). (a) Later an additional weak $h$ expression in the area of $h$ stripe 7 can be observed. (b) At late blastoderm $h$ is expressed in a pattern of five stripes. (c) The h-T/C lac $Z$ fusion gene construct, which drives $\beta$-galactosidase expression in the position of $h$ stripes 3 and 4 in wildtype embryos, directs $\beta$-galactosidase expression in a broad, anterior domain in embryos which lack bcd activity. Note that this pattern resembles the pattern of endogenous $h$ expression as observed in (a). (d) In late blastoderm embryos which lack $b c d$ activity the $\beta$-galactosidase expression pattern driven by the $\mathrm{h}-\mathrm{T} / \mathrm{C}$ lac $Z$ fusion gene construct does not change significantly. In early blastoderm embryos lacking nos activity, there is initial $h$ expression throughout the embryo except the terminal region (not shown). (e) As blastoderm formation proceeds, two stripes resolve from the broad $h$ expression domain in the anterior part of the embryo. (f) At late blastoderm $h$ is expressed in four stripes. $(\mathrm{g})$ In the absence of nos activity the $\mathrm{h}-\mathrm{T} / \mathrm{C}$ lac $Z$ construct drives $\beta$-galactosidase expression in a broad domain in the posterior half of the embryo, resembling the endogenous $h$ pattern in the posterior as seen in (e). (h) At beginning of gastrulation stronger $\beta$-galactosidase expression driven by the construct $\mathrm{h}-\mathrm{T} / \mathrm{C}$ lac $\mathrm{Z}$ can be observed at the anterior border of the posterior domain in an embryo lacking nos activity. 
2.2. Genetic control of stripe expression mediated by the $h$ stripe 3 / 4 element

Since the above studies suggested that $h$ stripe 3 and 4 elements might not be separable by deletion analysis, we asked by genetic means whether $h$ stripe 3 and 4 expression is regulated by different sets of trans- acting factors that may interact with interspersed target sequences for the third and fourth stripe. For this, we first examined expression of $\mathrm{h}-\mathrm{T} / \mathrm{C}$ lac $\mathrm{Z}$ construct in embryos that lack the activities of the maternal coordinate genes bicoid ( $b c d$ ), nanos (nos) and torso (tor), which are required to organize the anterior, the posterior and the terminal regions of the embryo, respec- a

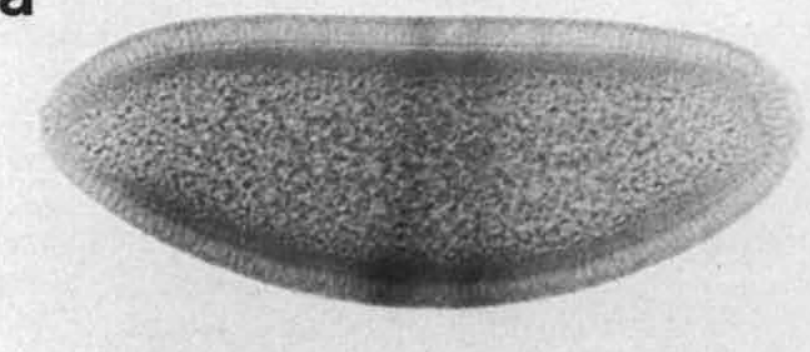

C

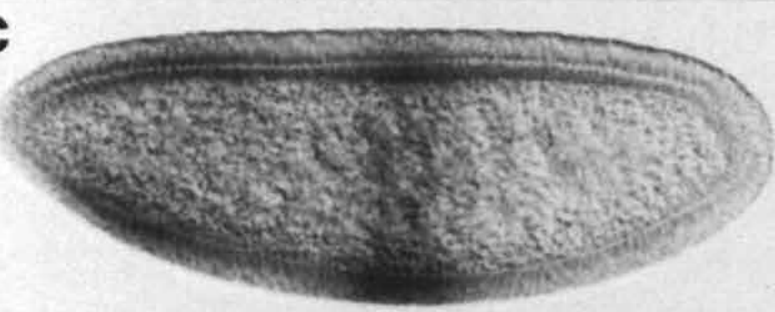

e

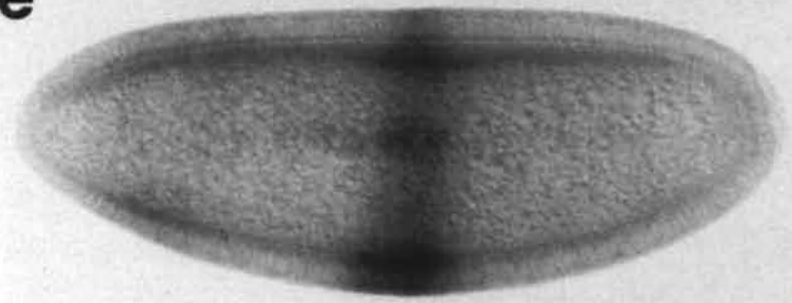

b

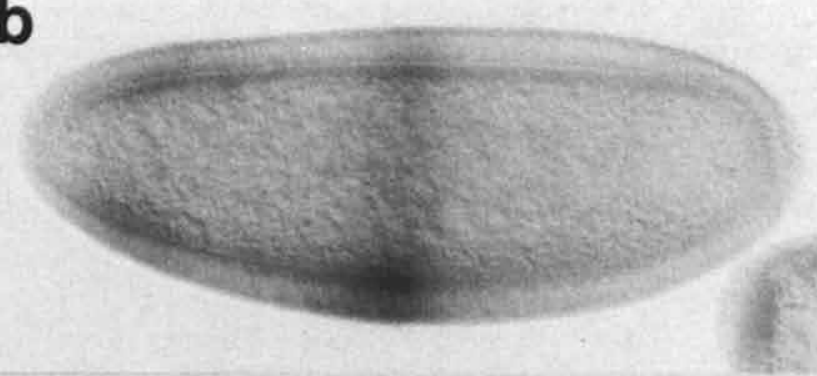

d

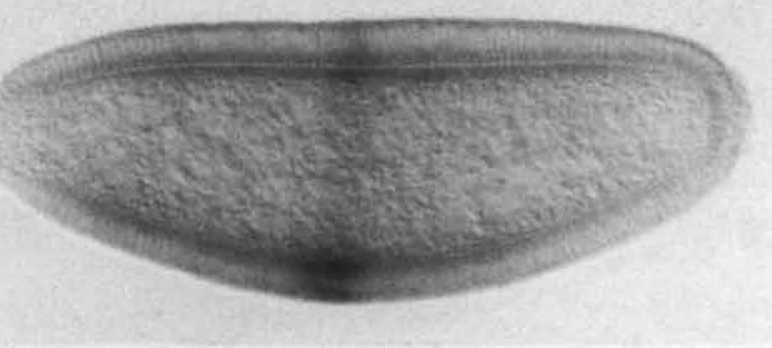

f

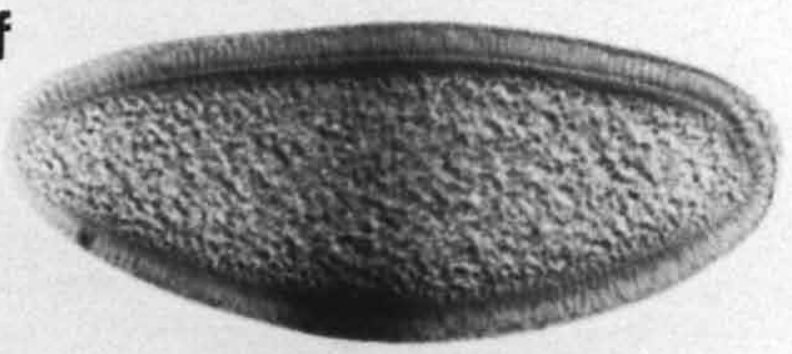

h

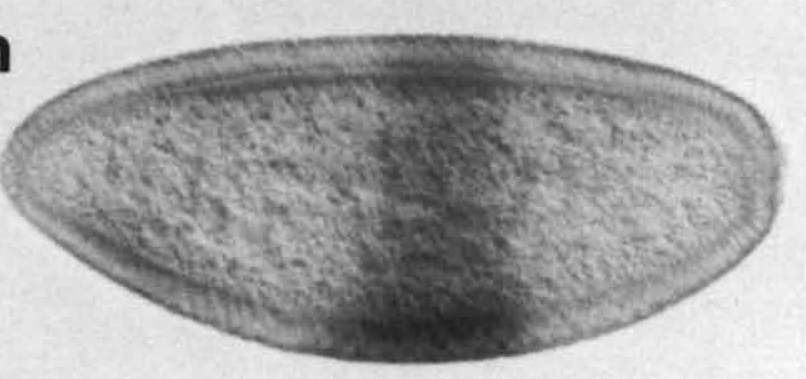

Fig. 4. Expression patterns of fusion gene constructs $h-T / C$ lac $Z$ and $h-T / R$ lac $Z$ in embryos lacking the activity of various zygotic segmentation genes. (a-d) $\beta$-galactosidase expression pattern driven by the construct $\mathrm{h}-\mathrm{T} / \mathrm{C}$ lac $Z$. (a) wildtype embryo showing a two striped pattern; (b) $h b$ embryo showing $\beta$-galactosidase expression in one broad stripe, which is shifted slightly towards anterior; (c) $K r$ embryo showing a single band of $\beta$-galactosidase expression in the middle of the embryo; (d) kni embryo showing $\beta$-galactosidase expression only in the area of $h$ stripe 3 . (e-h) $\beta$-galactosidase expression patterns driven by the construct h-T/R lac $Z$. (e) wildtype embryo showing a $\beta$-galactosidase expression domain in the middle of the embryo; (f) $h b$ embryo showing that the broad $\beta$-galactosidase expression domain is expanded and shifted slightly anteriorly; (g) $K r$ embryo showing that the $\beta$-galactosidase expression in the middle of the embryo is significantly reduced; (h) kni embryo showing that the expression domain is expanded towards posterior. 
tively (Nüsslein-Volhard et al., 1987). In the following, we focus on the question of how the two stripes are generated from the single band of expression, rather than on the spatial regulation of the initial expression domain itself.

There is no alteration of $\mathrm{h}-\mathrm{T} / \mathrm{C}$ lac $\mathrm{Z}$ transgene expression in embryos lacking tor activity (not shown). However, in embryos lacking bcd or nos activity, a broad domain of $\mathrm{h}-\mathrm{T} / \mathrm{C}$ lac $\mathrm{Z}$ gene expression is observed in the anterior and posterior regions of the embryo, respectively, which do not resolve into separate stripes (Fig. 3). The maternal coordinate gene activities $b c d$ and nos are required to control a variety of zygotic target genes, which themselves could also regulate $h$ expression (Schröder et al., 1988; Driever et al., 1989; Struhl et al., 1989; Eldon and Pirrotta, 1991, Kraut and Levine, 1991). Thus, the altered gene expression pattern observed in embryos lacking $b c d$ activity could be due to any combination of $b c d, h b$ and $g t$ activities. Analogously, the lack of nos activity results in the ectopic expression of maternal $h b$ in the posterior region of the embryo; this maternal $h b$ activity in turn represses the expression of the gap genes knirps (kni) and gt (Tautz, 1988; Rothe et al., 1989; Eldon and Pirrotta, 1991; Kraut and Levine, 1991; Pankratz et al., 1992). Therefore, in nos embryos, the regulatory effect on $h$ expression could be due to the ectopic presence of maternal $h b$ activity and/or the lack of zygotic $k n i$ and $g t$ activities. To test whether the effect of the maternal coordinate gene activity on $h$ stripe 3 and 4 expression is mediated by the zygotic gap gene activities, we placed the $\mathrm{h}-\mathrm{T} / \mathrm{C} \mathrm{lacZ}$ construct into various gap mutant embryos (Fig. 4).

Expression from $\mathrm{h}-\mathrm{T} / \mathrm{C}$ lac $\mathrm{Z}$ reporter gene is not altered in $g t$ mutants (not shown). In zygotic $h b$ mutants there is a single broad band of expression in place of the two separate stripes (Fig. 4b). In $K r$ mutants the $\mathrm{h}-\mathrm{T} / \mathrm{C}$ lac Z reporter gene is only weakly expressed in a single broad expression domain (Fig. 4c). The expression patterns of the reporter gene construct $h-T / R$ $\operatorname{lac} \mathrm{Z}, \mathrm{h}-\mathrm{T} / \mathrm{M} \operatorname{lac} \mathrm{Z}$ and $\mathrm{h}-\mathrm{M} / \mathrm{R} \operatorname{lac} \mathrm{Z}$ (which lack the sequences required to split the initial broad expression domain into the two stripes in wildtype embryos) were similar to the $\mathrm{h}-\mathrm{T} / \mathrm{C}$ lac $\mathrm{Z}$ expression patterns in the corresponding mutants (shown for construct h-T/R lacZ in Fig. 4f,g). These results suggest that the combined activities of $K r$ and $h b$ are required for the separation of $h$ stripe 3 and 4 expression in wildtype embryos, either directly or through the activity of another target gene.

In kni mutants, the expression of the h-T/C lac Z construct in the area of $h$ stripe 4 is absent (Fig. 4d). This observation could formally be interpreted as that $k n i$ is required to activate $h$ stripe 4 expression while having no effect on stripe 3 . If so, the expression patterns of $\mathrm{h}-\mathrm{T} / \mathrm{R} \operatorname{lac} \mathrm{Z}, \mathrm{h}-\mathrm{T} / \mathrm{M} \operatorname{lac} \mathrm{Z}$ and $\mathrm{h}-\mathrm{M} / \mathrm{R}$ lac Z reporter genes (which show a broad band of expression in wildtype embryos) should, in kni mutants, only result in a 'stripe 3 pattern' since contribution by stripe 4 expression would be eliminated. However, expression of these constructs in kni mutants leads to a single broadened domain which expands posteriorly (shown for construct $\mathrm{h}-\mathrm{T} / \mathrm{R}$ lac $\mathrm{Z}$ in Fig. $4 h$ ). Thus, the expression of $h-T / C$ lac $Z$ in position of $h$ stripe 3 in $k n i$ mutants is not likely to derive from the lack of kni-dependent activation of stripe 4, but rather from derepression of a kni-dependent repressor. In kni mutants, this repressor activity may expand into a region of $h$ stripe 4 , thereby preventing h-T/C lac $\mathrm{Z}$ expression. These results emphasize that the loss of $h$ stripe 4 expression of $\mathrm{h}-\mathrm{T} / \mathrm{C}$ lac $Z$ expression in kni mutants does not necessarily imply a separate genetic control of the two stripes; the reason for the posteriorly expanded band of $\mathrm{h}-\mathrm{T} / \mathrm{R} \operatorname{lac} \mathrm{Z}, \mathrm{h}-\mathrm{T} / \mathrm{M}$ lac $\mathrm{Z}$ and $\mathrm{h}-\mathrm{M} / \mathrm{R}$ lac $\mathrm{Z}$ expression in kni mutants is unclear at this point.

\subsection{Direct interaction of gap proteins with the $h$ stripe $3 / 4$ element in vitro}

The above genetic studies did not consistently indicate an independent control of $h$ stripe 3 and 4 expression. However, they showed that the gap genes are required for the proper establishment of the initial $h$ stripe 3 and 4 expression domain. We therefore asked whether the different gap proteins might directly interact with the cis-regulatory sequences of $h$. For this, the $900 \mathrm{bp} \mathrm{Stu} / \mathrm{Cla}$-fragment which drives stripe 3 and 4

\footnotetext{
Fig. 5. In vitro binding of HB- and KNI- protein to the $h 3 / 4$ cis-regulatory region. DNase I footprinting assays were performed with crude bacterial extracts of full-length HB and full-length KNI on three subfragments of the 900 bp StuI-ClaI regulatory region of $h$ stripes 3 and 4: (a)

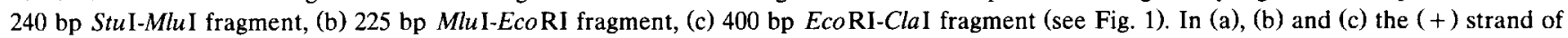
the DNA fragments is labeled. GA refers to a marker lane containing a Maxam-Gilbert reaction. For control, fragments were incubated with no extract (lane marked with -), or with control extract from bacteria containing the T7 expression vector alone without $h b$ or kni coding regions (lane C). In lanes 1 and 2 in (a-c) and lane 3 in (c), fragments were incubated with increasing amounts of HB extract. In lanes 4 and 5 in (a-c) and lane 6 in (c) they were incubated with increasing amounts of KNI extract. On the right side of each autoradiogram the orientation of the DNA fragment is shown (T, StuI; M, MluI; R, EcoRI; C, ClaI; see Fig. 1) and the binding sites are marked (HB: black boxes; KNI: stippled boxes). The orientation of the HB- and the KNI consensus binding sites within the protected areas are indicated by the arrows. Footprinting experiments were also performed with the (-) strand of the fragments (data not shown). For the distribution of the HB and KNI binding sites along the $900 \mathrm{bp} \mathrm{T/C}$ fragment see Fig. 6.
} 
expression in transgenic embryos was systematically tested for $h b, K r$ and $k n i$ protein binding sites (Fig. $5 \mathrm{ac})$. We could detect at least seventeen $h b$ protein
(HB) and five kni protein (KNI) binding sites distributed throughout the $900 \mathrm{bp}$ fragment (summarized in Fig. 6). By contrast, there were no $K r$ protein (KR)

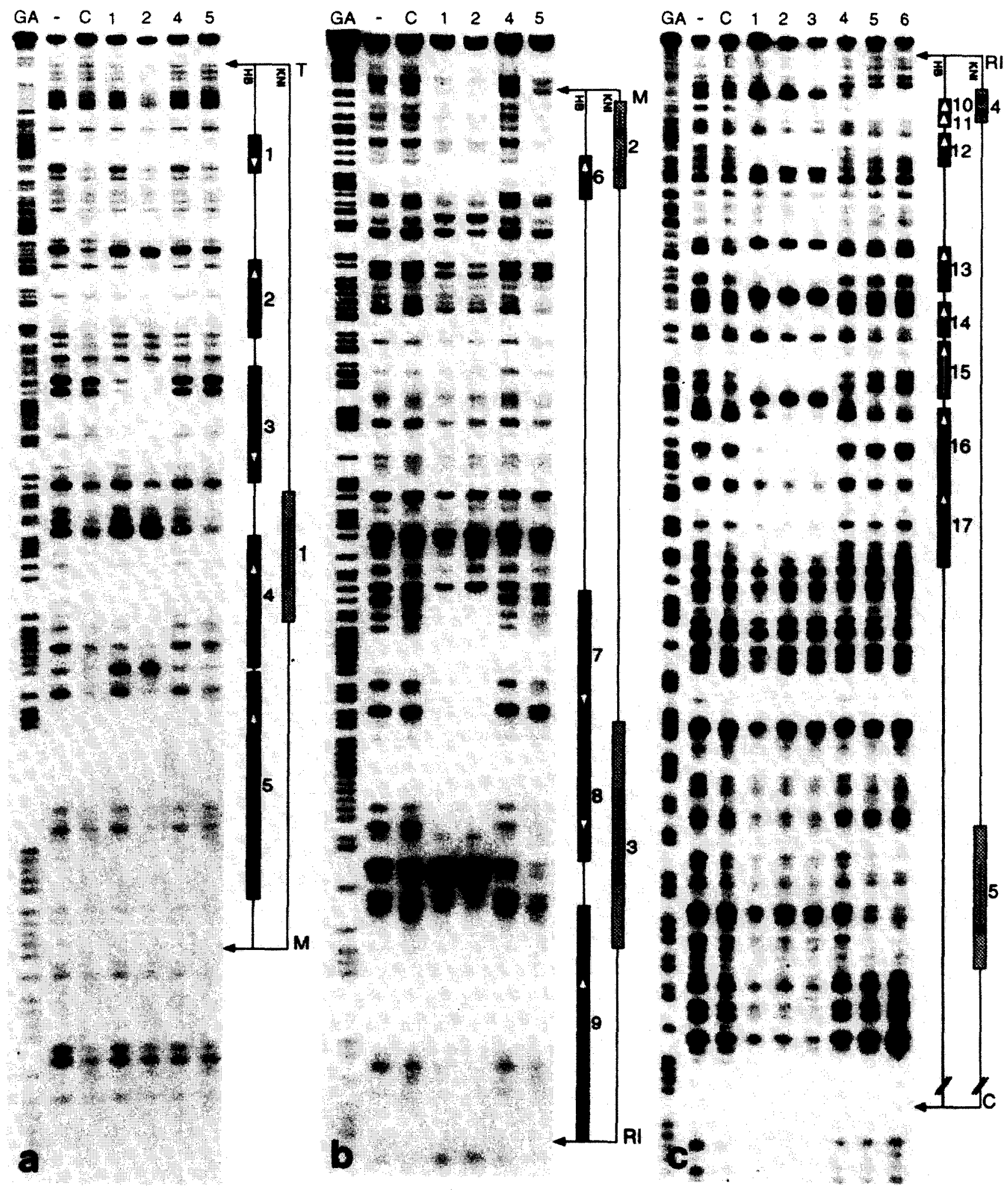


binding sites observed under the experimental conditions that were used for the detection of $\mathrm{KR}$ in vitro binding sites in other target genes (Pankratz et al., 1989; Zhang et al., 1991; Hoch et al., 1991). These results show the potential of direct $\mathrm{HB}$ and KNI interactions with the $h$ stripe $3 / 4$ cis-regulatory region, while KR is likely to interact indirectly.

\subsection{The ISR-element mediates runt-dependent repression in the center of the initial $h$ stripe $3 / 4$ expression domain}

Although each of the gap genes $h b, K r$ or $k n i$ might be required to determine the spatial limits of the initial $h$ stripe $3 / 4$ expression domain, the above results demonstrate that the activity of only one of them can not mediate the separation of the stripes within the initial $h$ stripe $3 / 4$ expression domain. Thus, it might be the combined direct action of two or several of these genes which leads to the splitting of the broad expression domain. Alternatively, the ISR-element might be responsive to a gap gene-dependent primary pair rule gene.

The only known gene that is expressed precisely between $h$ stripe 3 and 4 , and thus a candidate for a repressor that separates the two $h$ stripes, is the third stripe of the primary pair rule gene run (Gergen and
Butler, 1988; Ingham and Gergen, 1988). It has been described earlier that the endogenous $h$ expression is altered in run mutant embryos (Ingham and Gergen, 1988; Hooper et al., 1989; Carroll and Vavra, 1989; Klingler and Gergen, 1993); among the alterations, ectopic expression of $h$ is observed between stripes 3 and 4 and a clear separation into two stripes does not occur at blastoderm. Furthermore, there is a broad contiguous region of run expression posterior to $h$ stripe 3 in kni mutant embryos (Klingler and Gergen, 1993), which could potentially account for the absence of stripe 4 expression of h-T/C lac $Z$ construct in $k n i$ mutant embryos (see Fig. 4d). We therefore examined whether it is run activity that is required for the separation of $h$ stripe 3 and 4 by placing the h-T/C lac $Z$ construct into run mutant embryos. In such embryos, a band of expression is observed in place of the two stripes (Fig. 7). A similar result is observed when the h-M/A lac Z construct is placed into run mutant embryos (data not shown). This indicates that the splitting of the initially broad $h$ stripe $3 / 4$ expression domain requires run activity. Since the expression patterns of the $\mathrm{h}-\mathrm{T} / \mathrm{R}$ lac $\mathrm{Z}$ construct and the two subconstructs $\mathrm{h}-\mathrm{T} / \mathrm{M}$ lac $\mathrm{Z}$ and $\mathrm{h}-\mathrm{M} / \mathrm{R}$ lac $\mathrm{Z}$ in wildtype embryos are similar to that of $\mathrm{h}-\mathrm{T} / \mathrm{C}$ lac $Z$ expression in run embryos, those former constructs most likely

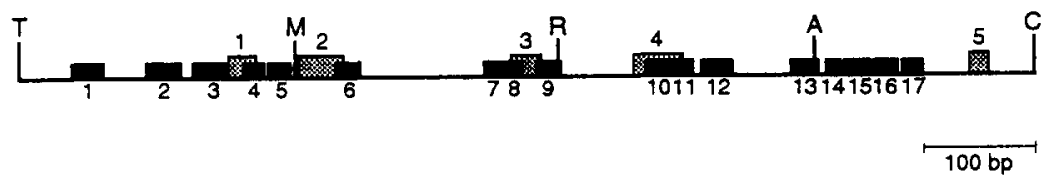

$\begin{array}{ll}\text { hb1 } & \text { GAAGAAAAAAA } \\ \text { hb2 } & \text { ACGCAAAAAAT } \\ \text { hb3 } & \text { ACATAAAAAGG } \\ \text { hb4 } & \text { TCATAAAAACA } \\ \text { hb5 } & \text { GGAAAAAAAAT } \\ \text { hb6 } & \text { CGCTAAAAATG } \\ \text { hb7 } & \text { TGACAAAAAAG } \\ \text { hb8 } & \text { AAACAAAAAAG } \\ \text { hb9 } & \text { CACTAAAAATC } \\ \text { hb10 } & \text { GAACAAAAAAT } \\ \text { hb11 } & \text { TCATAAAAATA } \\ \text { hb12 } & \text { CCACAAAGAAG } \\ \text { hb13 } & \text { AAATAAAAAAT } \\ \text { hb14 } & \text { GCCAAAAAGAA } \\ \text { hb15 } & \text { CCACAAAAAAG } \\ \text { hb16 } & \text { AGCTAAAAATT } \\ \text { hb17 } & \text { CCACAAAAATT } \\ & \\ & \text { ACA AAAAAA } \\ & \text { C CAAA }\end{array}$

$\begin{array}{ll}\text { kni1 } & \text { GACCGAAATA } \\ \text { kni2 } & \text { GATCTCAATG } \\ \text { kni3 } & \text { GATCTCGTTC } \\ \text { kni4 } & \text { GAGCGACCTC } \\ \text { kni5 } & \text { GTTCTAATATA } \\ & \text { AATCTGGACT } \\ & \text { GATC GA }_{\text {TC }}^{\text {AATG }}\end{array}$

Fig. 6. Schematic representation of HB and KNI in vitro binding sites within the 900 bp $h$ stripe 3 and 4 cis-regulatory region. Black bars represent $\mathrm{HB}$ binding sites, stippled bars KNI binding sites. Numbers refer to the binding sites in Fig. 5 . Note that four of five sites protected by KNI overlap with HB protected sites. The sequences of the KNI- and HB-binding sites are listed below. Two of the KNI binding sites contain two copies of the consensus sequence. Alignment of the HB sites reveals a consensus sequence, shown in the bottom left column, similar to those previously determined (Stanojevic et al., 1989; Treisman and Desplan, 1989; Pankratz et al., 1992; Hoch et al., 1991; Zhang et al., 1991). The KNI consensus sequence deduced from the alignment of the KNI binding sites, shown in the bottom of the right column, is similar to the KNI consensus sequence published recently by Hoch et al. (1992). (A, Aval; C, ClaI; M, MluI; R, Eco RI; T, StuI). 

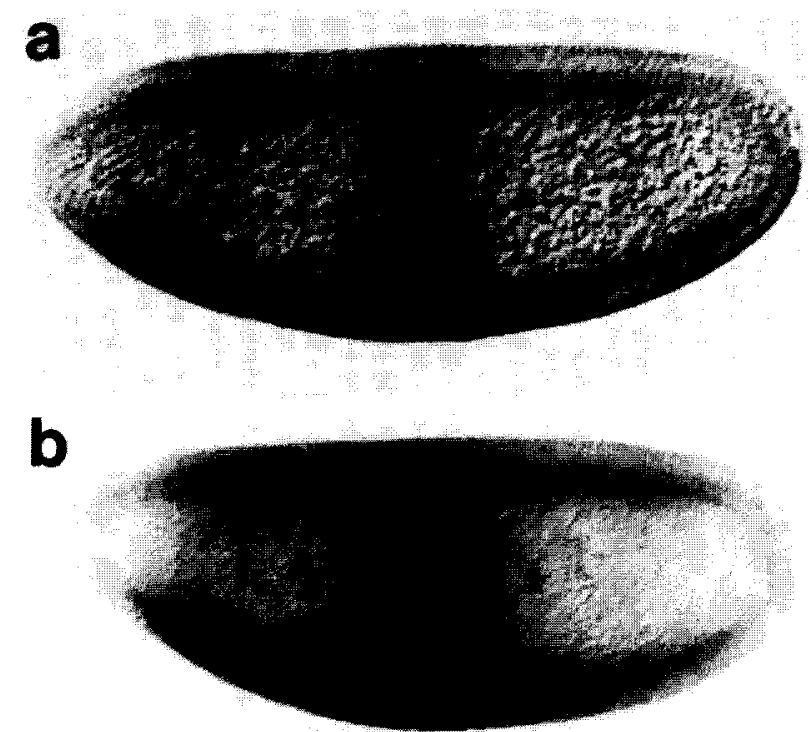

Fig. 7. Expression pattern of the fusion gene construct h-T/C lacZ in embryos lacking the activity of the primary pair-rule gene run. (a) Wildtype embryo showing $\beta$-galactosidase expression in two stripes in the blastoderm embryo. (b) run embryo showing $\beta$-galactosidase expression in a broad band; separation of the expression domain into a two striped pattern does not occur at blastoderm.

have lost the sequences required to respond to run activity. These findings are consistent with the argument that the ISR-element, located downstream of the EcoRI site, contains run responsive sequences that mediate repression within the $h$ stripe $3 / 4$ interstripe region in wildtype embryos. Thus, the setting of $h$ stripe 3 and 4 expression follows a 'two-step mode' of regulation: activation of gene expression in a single broad band and subsequent repression in response to another primary pair rule gene activity in the interstripe region.

\section{Discussion}

Our results show a 'two-step mode' for stripe formation along the anterior-posterior axis of the Drosophila embryo: $h$ stripe 3 and 4 expression is mediated by a common regulatory element in an initial broad $h$ stripe $3 / 4$ expression domain which covers an area of three stripe equivalents. In a second step, repression provided by another primary pair rule gene, run, overrides activation in the interstripe region and thereby creates two evenly spaced stripes. This mode of stripe formation differs from the mechanism by which stripes are generated through individual regulatory elements each mediating expression in a direct response to activation or repression by maternal and zygotic gap gene activities (Goto et al., 1989; Harding et al., 1989; Stanojevic et al., 1989, 1991; Pankratz et al., 1990; Howard and
Struhl, 1990; Riddihough and Ish-Horowicz, 1991; Small et al., 1991, 1992).

In contrast to the previous studies on the primary pair rule genes, analysis of the secondary pair rule gene $f t z$ indicated that a common element, termed the 'zebra element', gives rise to $\mathrm{ftz}$ expression of all seven stripes (Hiromi et al., 1985; Hiromi and Gehring, 1987). The stripe pattern of $f t z$ expression is thought to come about through selective enhancement and/or repression in stripes within this contiguously activated domain, most likely through a combination of primary pair rule gene activities (Carroll and Scott, 1986; Ingham and Gergen, 1987). Stripe 3 and 4 expression of $h$ appears to incorporate a combination of the two basic mechanisms outlined above. Although the detailed analysis of the genetic components that activate and spatially restrict the initial $h$ stripe $3 / 4$ expression domain has not been the focus of our present study, it is interesting to note that the $h$ stripe $3 / 4$ expression domain covers almost precisely the expression domain of the gap gene $K r$, and that the genetic requirements for setting up these domains are strikingly similar. Thus it appears likely that in a manner analogous to $K r$, control of initial $h$ stripe $3 / 4$ expression involves the combined activities of $h b$ and $b c d$ for activation, and local repression by various gap gene activities to spatially delimit the expression domain (Hülskamp et al., 1990; Hoch et al., 1991,1992). This proposal is consistent with the altered $h$ stripe $3 / 4$ expression patterns in the various maternal and zygotic mutants analysed (see Figs. 3, 4 and 7), and with in vitro DNA-binding studies indicating that the corresponding gene products directly bind to multiple sites throughout the $h$ stripe $3 / 4$ cis-acting element. The initial activation of the $h$ stripe $3 / 4$ expression domain is therefore reminiscent of the setting of a gap gene expression domain as well as the formation of single pair rule stripes such as eve stripe 2 (Frasch and Levine, 1987; Goto et al., 1989; Small et al., 1991, 1992) or $h$ stripe 6 (Pankratz et al., 1990; Riddihough and Ish-Horowicz, 1991). The subsequent splitting of this domain however, through run-dependent repression, resembles the mechanism of stripe generation of the secondary pair rule genes such as ftz. Thus, the generation of stripe gene expression of primary pair rule genes in the blastoderm embryo involves at least two different modes: through individual stripe elements as in the case of eve stripe 2 and $h$ stripe 6 expression, or through a 'two step mode' involving interstripe repression by a primary pair rule gene expressed in a complimentary pattern.

In the absence of either the coarsely characterized ISR-element or run activity, $h$ stripes 3 and 4 do not resolve. Instead, the broad band of the $h$ stripe $3 / 4$ expression remains in the central region of the embryo, suggesting that run-activity is able to override $h$ stripe 
$3 / 4$ activation through an interaction mediated by the ISR-element. This would account for the lack of $h$ stripe 4 expression in kni mutants, since in these embryos run is ectopically expressed in a region spanning $h$ stripe 4 expression domain (Klingler and Gergen, 1993). However, if run activity by itself would be sufficient to override activation, one should expect repression of $h$ stripe 3/4 expression not only in kni, but also in $K r$ mutant embryos where run is similarly expressed in a broad region covering the $h$ stripe $3 / 4$ expression domain (Klingler and Gergen, 1993). How is it that run activity provides ISR-element-dependent repression in $k n i$ but not in $K r$ mutant embryos? One possibility is that the run gene product may require for its repressor function a partner molecule such as the $K r$ protein or a $K r$-dependent gene product. This would explain why in the absence of $\mathrm{Kr}$ activity run has lost the ability to repress, while it functions as a repressor in a region of combined $K r$ and run activities, as is found in kni mutants. It has recently been shown that run protein is localized in the nucleus, and that its putative primary sequence contains a protein motif that is conserved in the human acute myeloma leukemia factor AML1 (Kania et al., 1990; Daga et al., 1992). This human protein is likely to act as a transcriptional regulator, leaving open the question whether run protein can function as a transcriptional repressor directly or through interaction with a protein such as $K r$.

In Drosophila, all of the pair rule stripes are formed during the syncytial stage of development. However, it has been recently demonstrated that in the beetle Tribolium only the first two $h$ stripes are formed during syncytial blastoderm, and the more posterior stripes are generated in a cellular field of segment primordia (Sommer and Tautz, 1993). Interestingly, $h$ stripes 3 and 4 of Tribolium are also derived from a single expression domain, initially covering the $K r$ expression domain. Although the initial expression domain arises during syncytial blastoderm, the splitting of this domain into two separate stripes 3 and 4 occurs during the time when cellularization, and subsequent cell proliferation and movements have produced the growing germ band (Sommer and Tautz, 1993). Thus, it may be that the mechanism suggested here for the generation of Drosophila $h$ stripes 3 and 4 is efficacious for delineating striped expression patterns in both syncytial and cellular environments.

\section{Materials and methods}

\subsection{Constructions of h-lac Z fusion genes and germ line transformations}

The $1.7 \mathrm{~kb} C l a \mathrm{I}$ fragment of the $14 \mathrm{~kb} h$ upstream region (Howard et al., 1988; Rushlow et al., 1989) was inserted into the Bluescript vector DNA ((pBst) Stratagene). This fragment and subfragments (see Fig. 1) were subcloned (after filling reactions) into the endfilled Eco RI site of the $\mathrm{KrZ}$ pCaSpeR P-element vector (Hoch et al., 1991); the resulting fusion gene constructs used for germ line transformation as described (Rubin and Spradling, 1982). Transgenic lines were established and their embryonic progeny assayed for $\beta$-galactosidase expression by antibody staining (see below). For each experiment at least two independent transformant lines were analysed.

\subsection{Genetics and antibody staining}

The homozygous P-element transgenes were crossed into several mutant lines such as $b c d^{\mathrm{EI}}, h b^{7 \mathrm{M}}, n o s^{\mathrm{L} 7}$, $K r^{1}, k n i^{\mathrm{FC} 13}$ and $r u n^{\mathrm{YP}}$ (Tearle and Nüsslein-Volhard, 1987). Embryos were either identified by the genotype of the mother (nos, $b c d$ ), or by doublestaining with the corresponding antibodies $(h b, K r, k n i)$. In the case of $r^{\mathrm{YP}}$, embryos lacking run activity were identified by the altered expression pattern observed in a quarter of the embryos. Antibody staining of whole mount embryos was carried out as described (Macdonald and Struhl, 1986) using the Vectastain ABC Elite horseradish peroxidase system.

\subsection{Footprinting experiments}

The full-length $h b$ bacterial expression vector (pEThb) was kindly provided by Dr. Tautz (Tautz et al., 1987; Hoch et al., 1991). The full-length kni bacterial expression vector (pETkni) was previously described by Pankratz et al. (1990). Transformation of bacteria, induction of $\mathrm{T} 7$ expression vectors and preparation of bacterial crude extract were done as described (Kadonaga et al., 1987). The fragments were labeled by end-filling with Klenow enzyme as described (Sambrook et al., 1989). For end-labeling of the (+) strand, fragments were cut out with XhoI/Pst I from the corresponding pBst clones. Footprinting experiments and Maxam-Gilbert sequencing were done as described (Kadonaga et al., 1987).

\section{Acknowledgements}

We thank K. Howard for the anti- $h$ antibodies. We would also like to thank our colleagues in the lab for critical discussions and Mrs E. Vetter for preparing the manuscript. The work was supported by the Max-Planck Society, the Deutsche Forschungsgemeinschaft and the Fonds der Chemischen Industrie. C.H. is a Fellow of the Studienstiftung des Deutschen Volkes. 


\section{References}

Akam, M. (1987) Development 101, 1-22.

Carroll, S. (1990) Cell 60, 9-16.

Carroll, S. and Scott, M. (1986) Cell 45, 113-126.

Carroll, S. and Vavra, S. (1989) Development 107, 673-683.

Daga, A., Tighe, J.E. and Calabi, F. (1992) Nature 356, 484.

Driever, W., Thoma, G. and Nüsslein-Volhard (1989) Nature 340, 363-367.

Eldon, E. and Pirrotta, V. (1991) Development 111, 367-378.

Frasch, M. and Levine, M. (1987) Genes Dev. 1, 981-995.

Gergen, P. and Butler, B. (1988), Genes Dev. 2, 1179-1193.

Goto, T., Macdonald, P. and Maniatis, T. (1989) Cell 57, 413-422.

Harding, K., Rushlow, C., Doyle, H.J., Hoey, T. and Levine, M. (1986) Science 233, 953-959.

Harding, K., Hoey, T., Warrior, R. and Levine, M. (1989) EMBO J. $8,1025-1212$.

Hiromi, Y., Kuroiwa, A. and Gehring, W. (1985) Cell 43, 603-613.

Hiromi, Y. and Gehring, W. (1987) Cell 50, 963-974.

Hoch, M., Seifert, E. and Jäckle H. (1991) EMBO J. 10, 2267-2278.

Hoch, M., Gerwin, N., Taubert, H. and Jäckle, H. (1992) Science 256, 94-97.

Hooper, K., Parkhurst, S. and Ish-Horowicz, D. (1989) Development $107,489-504$.

Howard, K. (1988) Development 104 (Suppl.), 35-50.

Howard, K. (1990) Sem. Cell Biol., 1, 161-172

Howard, K. and Ingham, P. (1986) Cell 44, 949-957.

Howard, K., Ingham, P. and Rushlow, C. (1988) Genes Dev. 2, 1037-1046.

Howard, K. and Struhl, G. (1990) Development, 110, 1223-1231.

Hülskamp, M., Pfeifle, C. and Tautz, D. (1990) Nature 346, 577-580. Ingham, P. (1988) Nature 335, 25-34.

Ingham, P. and Gergen, P. (1988) Development 104 (Suppl.), 51-60.

Kania, M., Bonner, A., Duffy, J., Gergen, P. (1990) Genes Dev. 4, $1701-1713$.

Kadonaga, J.T., Carner, K.R., Masiarz, F.R. and Tjian, R. (1987) Cell 51, 1079-1090.

Klingler, M. and Gergen, P. (1993) Mech. Dev. 43, 3-19.

Kraut, R. and Levine, M. (1991) Development 111, 601-609.

Lardelli, M. and Ish-Horowicz, D. (1993) Development 118, 255-266.

Macdonald, P. and Struhl, G. (1986) Nature 324, 537-545.
Nüsslein-Volhard, C. and Wieschaus, E. (1980) Nature 287, 795-801.

Nüsslein-Volhard, C., Wieschaus, E. and Jürgens, G. (1982) Verh. Dtsch. Zool. Ges. 1982, 91-104.

Nüsslein-Volhard, C., Frohnhöfer, H.G. and Lehmann, R. (1987) Science 238, 1675-1681.

Pankratz, M. and Jäckle, H. (1990) Trends Genet. 6, 287-292.

Pankratz, M. and Jäckle, H. (1993) In: Development of Drosophila, Cold Spring Harbor Laboratory Press (in press)

Pankratz, M., Hoch, M., Seifert, E. and Jäckle, H. (1989), Nature $341,337-340$.

Pankratz, M., Busch, M., Hoch, M., Seifert, E. and Jäckle, H. (1992) Science 255, 986-989.

Pankratz, M., Seifert, E., Gerwin, N., Billi, B., Nauber, U. and Jäckle, H. (1990) Cell 61, 309-317.

Riddihough, G. and Ish-Horowicz, D. (1991) Genes Dev. 5, 840-854.

Rothe, M., Nauber, U. and Jäckle, H. (1989) EMBO J. 8, 3087-3094.

Rubin, G. and Spradling, A. (1982) Science 218, 348-353.

Rushlow, C., Hogan, A., Pinchin, S., Howe, K. Lardelli, M. and Ish-Horowicz, D. (1989) EMBO J. 8, 3095-3013.

Sambrook, J., Fritsch, E.F. and Maniatis, T. (1989) Molecular Cloning, A Laboratory Manual. Cold Spring Harbor Laboratory Press, Cold Spring Harbor, NY.

Schröder, C., Tautz, D., Seifert, E. and Jäckle, H. (1988) EMBO J. 7, 2882-2887.

Small, S., Kraut, R., Hoey, T., Warrior, R. and Levine, M. (1991) Genes Dev. 5, 827-839.

Small, S., Blair, A. and Levine, M. (1992) EMBO J. 11, 4047-4057.

Sommer, R. and Tautz, D. (1993) Nature 361, 448-450.

Stanojevic, D., Hoey, T. and Levine, M. (1989) Nature 341, 331-337.

Stanojevic, D., Small, S. and Levine, M. (1991) Science 254, 13851387.

Struhl, G., Struhl, K. and Macdonald, P. (1989) Cell 57, 1259-1273.

Tautz, D. (1988) Nature 332, 281-284.

Tautz, D., Lehmann, R., Schnürch, H., Schuh, R., Seifert, E., Kienlin, A., Jones, K. and Jäckle, H. (1987) Nature 327, 383-389.

Tearle, R. and Nüsslein-Volhard, C. (1987) DIS 66, 209-269.

Treisman, J. and Desplan, C. (1989) Nature 314, 335-337.

Weigel, D., Seifert, E., Reuter, D. and Jäckle, H. (1990) EMBO J. 9, 1199-1206.

Zhang, C., Müller, J., Hoch, M., Jäckle, H. and Bienz, M. (1991) Development 113, 1171-1179. 